\title{
SMALL INTESTINE ILEUS IN ADULT PATIENTS
}

\author{
Plachkov I., V. Bozhkov, Pl. Chernopolsky, T. Ivanov \\ Second Department of Surgery, UMHAT “St. Marina” - Varna
}

Reviewed by: assoc. prof. V. Ignatov

\section{SUMMARY}

Small intestine intussusceptions caused by malignant tumor is very rare disease, not expected from the surgeons. The course of the disease usually is acute and non specific. Treatment is surgical with justified risk of one stage operation because of the advanced years of the patients.

\section{INTRODUCTION}

Small intestine tumors are very rare. Although the considerable length of the small intestines (about $75 \%$ of whole GIT length), their cancer rate is very little $-1,75-6,5 \%$ of all gastrointestinal malignancies (1). Small bowel intussusceptions as a cause for intestinal obstruction is mostly in children, but very rare in adult patients - just about $5 \%$ of all intussusceptions and 0,003-0,02\% of all admitted in hospital adults $(2,3)$. The main difference is that in children the intussusceptions is idiopathic in $90 \%$, but in adults usually there is a pathological abnormality (70-90\% of cases).

\section{CASE REPORT}

We report about an 83 years old patient admitted in the Second Department of surgery as an emergency case. The patient presents with signs and symptoms of small bowel obstruction with prescription about 24 hours - acute pain in

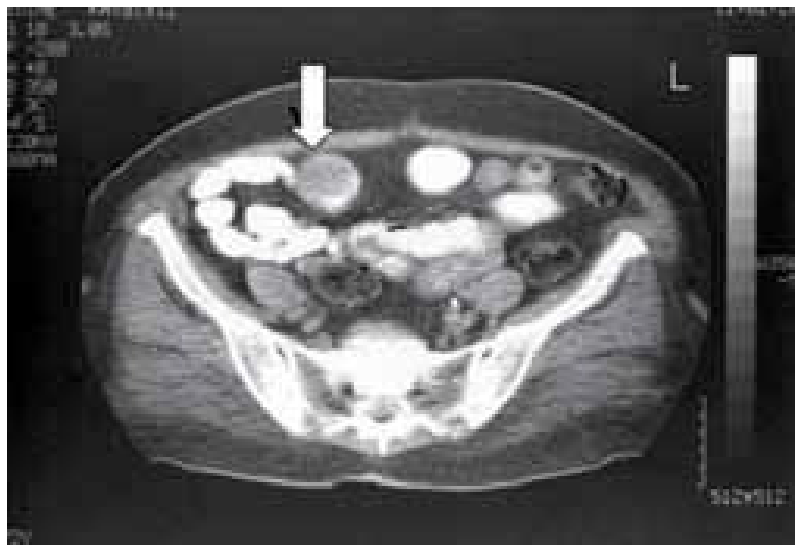

Fig. 1. CT scan reveals a small intestine tumor

\section{Address for correspondence:}

I. Plachkov, Second dept. of surgery, MHAT "Sv. Marina", Medical university - Varna, BG-9002, Varna, 1, Hristo Smirnenski Str. e-mail: iplachkov@mail.bg upper abdomen, nausea, vomiting; laboratory data of inflammation; abdominal X-rays data of obstructive small intestines disease with fluid levels in the stomach. CT scan reveals a small intestine tumor (fig. 1). An emergent surgical intervention was performed - an intussusception of the initial part of the jejunum at about $50 \mathrm{~cm}$ from lig. Treize with distended small bowel loop before it was established (fig. 2), a tumor formation in the intussusception part of the bowel (fig. 3), involved lymph nodes in the mesoradix, no involvement of paraaortal lymph nodes and lesions in the liver. A resection of the jejunum was performed with T-L anastomosis. The patient was discharged with normal postoperative period. The histological findings present an anaplastic malignant blastoma - undifferentiated carcinoma of small intestine with a metastasis in one lymph node.

\section{DISCUSSION}

Small intestine intussusceptions in adult patients are often unexpected for the surgeons. Type of digested food and peristaltic activity has a relation with this disease. The clinical presentation usually is chronic with non specific symptoms $(5,6)$. Abdominal pain is the most typical symptom, followed by nausea and vomiting. Palpable abdominal mass presents in $24-42 \%$ of cases. In about $30 \%$, malignant lesions (primary or metastatic) are the cause for intussusceptions. There is no procedure, which can be considered as golden standard in diagnosis of small intestine intussusceptions. Abdominal X-rays reveal the level of obstruction. Ultrasound scan diagnosis is an accident. CT scan is the most effective diagnostic procedure, which can reveal to us presence of tumor formation (4). Usually the disease is diagnosed intraoperative. The surgical intervention generally involves resection of the affected intestine, sometimes block resection with restitution of the GIT at one stage. The increased risk of one stage operation is justified, because of the place of the eventual enterostomy at an initial part of GIT, respectively loss of liquids and nutritious substances and the advanced years of the patients. 


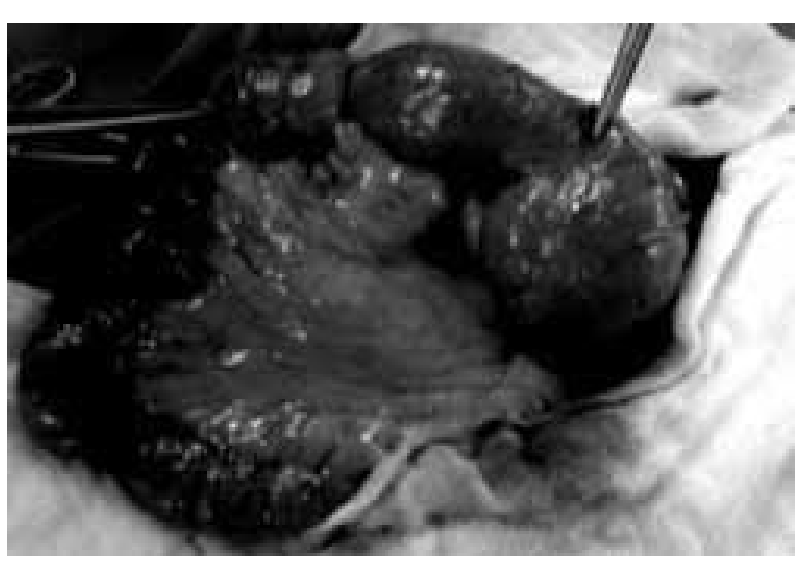

Fig. 2. Small bowel intussusceptions
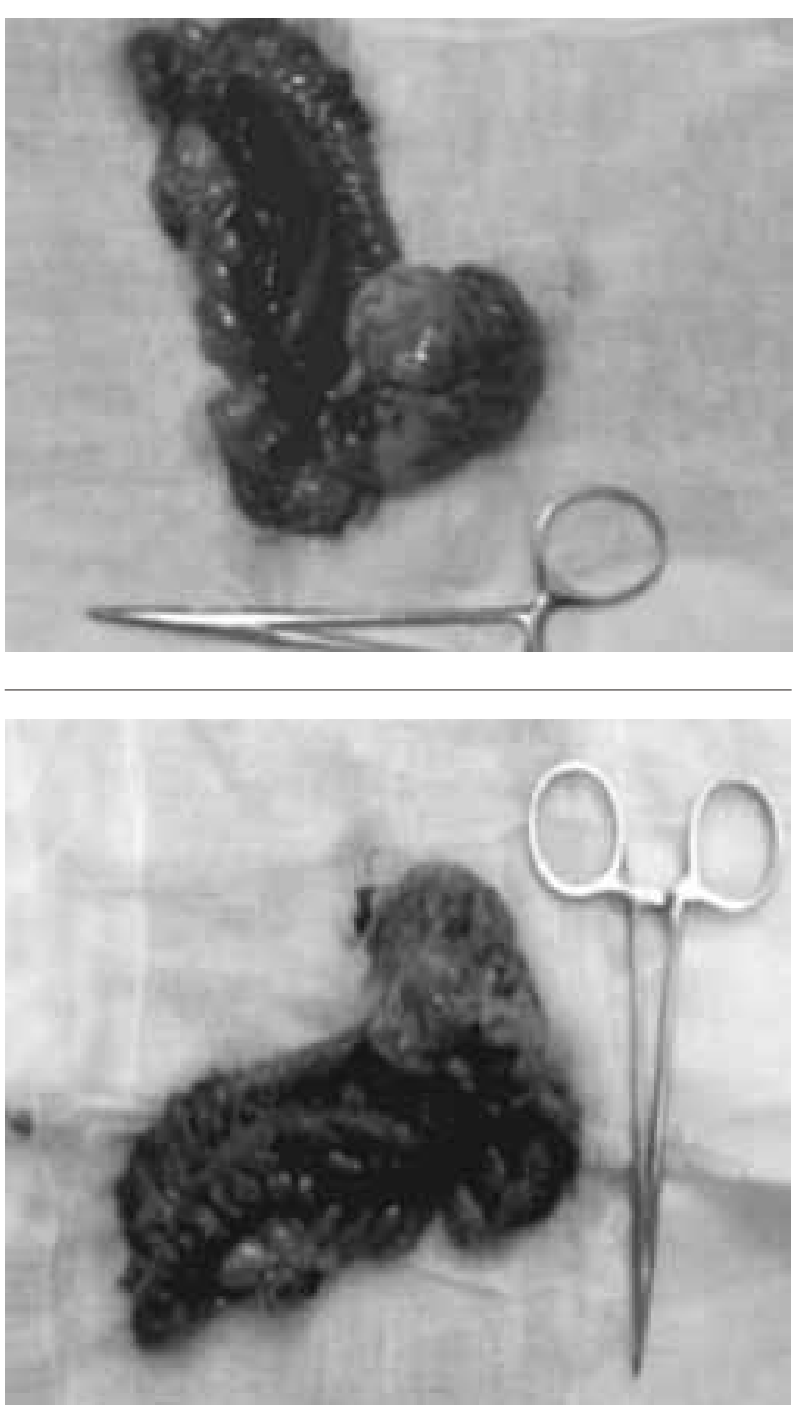

Fig.3. Tumor formation in the intussusception part of the bowel

\section{REFERENCES}

1. Azar T, Berger DL. Adult intussusception. Ann Surg 1997;226: 134-138

2. Begos DG, Sandor A, Modlin IM. The diagnosis and management of adult intussusception. $\mathrm{Am} \mathrm{J}$ Surg 1997; 173: 88-94

3. Weilbaecher D, Bolin JA, Hearn D, Ogden W $2^{\text {nd }}$ Intussusception in adults. Review of 160 cases. Am J Surg 1971; 121: 531-535

4. Felix EL, Cohen MH, Bernstein AD, Schwartz JH. Adult intussusception; case report of recurrent intussusception and review of the literature. Am J Surg 1976; 131: 758-761

5. Tan KY, Tan SM, Tan AG, Chen CY, Chng HC, Hoe MN. Adult intussusception: experience in Singapore. ANZ J Surg 2003; 73: 1044-1047

6. Wang LT, Wu CC, Yu JC, Hsiao CW, Hsu $\mathrm{CC}$, Jao SW. Clinical entity and treatment strategies for adult intussusceptions: 20 years' experience. Dis Colon Rectum 2007; 50: 1941-1949 